\title{
Plano Municipal de Educação de Taubaté: análise do processo de monitoramento e avaliação
}

\author{
Municipal Education Plan of Taubate: monitoring process analyze
}

\author{
Eduardo Castilho \\ Mestre em Formação de Gestores Educacionais \\ Universidade Cidade de São Paulo - UNICID. \\ São Paulo, SP - Brasil. \\ professorecastilho@gmail.com \\ Angela Maria Martins \\ Doutora em Educação \\ Fundação Carlos Chagas - FCC \\ Universidade Cidade de São Paulo - UNICID. \\ São Paulo, SP - Brasil. \\ ange.martins@uol.com.br
}

Resumo: O artigo tem o propósito de analisar o processo de monitoramento e avaliação do Plano Municipal de Educação de Taubaté (2015 - 2025), discutindo ações realizadas por instâncias previstas pela Secretaria Municipal de Educação, para incentivar a participação da sociedade civil no que condiz ao monitoramento e avaliação do PME. Trata-se de pesquisa qualitativa ancorada em pesquisa bibliográfica, análise documental e realização de entrevistas semiestruturadas com técnicos da Secretaria Municipal de Educação (SME), Comissão de Educação da Câmara e membros do Conselho Municipal de Educação (CME).

Palavras chave: planejamento educacional; plano municipal de educação; políticas públicas educacionais.

Abstract: This paper aims to analyze the monitoring process and evaluation of the Municipal Education Plan (2015 - 2025), it discusses had taken actions from public authorities foreseen activities by the Education Municipal Secretary to encourage civil society's participation concerning monitoring and evaluation of PME. This is qualitative research anchored in bibliographic research, document analysis, and a semi-structured interview with technicians from the Education Municipal Secretary, the Education Commission of Municipal Chambar, and the municipal Council for Education.

Keywords: educational planning; municipal education plan; public education policies.

Cite como

(ABNT NBR 6023:2018)

CASTILHO, Eduardo; MARTINS, Angela Maria. Plano Municipal de Educação de Taubaté: análise do processo de monitoramento e avaliação. Dialogia, São Paulo, n. 40, p. 1-15, e20538, jan./abr. 2022. Disponível em: https://doi.org/10.5585/40.2022.20538.

American Psychological Association (APA)

Castilho, E., \& Martins, A. M. (2022, jan./abr.) Plano Municipal de Educação de Taubaté: análise do processo de monitoramento e avaliação. Dialogia, São Paulo, 40, p. 1-15, e20538. https://doi.org/10.5585/40.2022.20538. 


\section{Introdução}

O presente artigo tem como objeto de análise o Plano Municipal de Educação de Taubaté, com o propósito de caracterizar e discutir as ações de monitoramento e avaliação emanadas pelas instâncias previstas em lei. O estudo - ancorado no campo das políticas educacionais - optou por uma abordagem metodológica de natureza qualitativa baseada em pesquisa bibliográfica, análise documental e realização de entrevistas semiestruturadas com técnicos da Secretaria Municipal de Educação (SME), Comissão de Educação da Câmara e membros do Conselho Municipal de Educação (CME). O contexto de análise é o município de Taubaté situado na Região Metropolitana do Vale do Paraíba e Litoral Norte Paulista com Índice de Desenvolvimento Humano (IDHM) de 0,800 (PNUD, 2013)

Incialmente, vale destacar que, no que concerne às políticas públicas, Souza (2006) as define como área do conhecimento que busca, ao mesmo tempo, "colocar o governo em ação" e/ou analisar essa ação (variável independente) e, quando necessário, propor mudanças no rumo ou curso dessas ações (variável dependente). Na mesma direção, a análise de políticas públicas tem como um de seus objetivos, contribuir com a solução de problemas provocados pela ação do Estado, bem como entender suas causas e consequências, condicionadas por um contexto específico em determinado espaço de tempo.

Cury (1998) expõe que os Planos correspondem a programas de realizações para serem cumpridos e executados em um certo período (definição cronológica), dentro de objetivos a serem atingidos e para os quais se pleiteiam os meios, inclusive pecuniários, necessários para a implementação adequada. Assim, Planos representam um esboço com descrições minuciosas capazes de definir um caminho acerca de um futuro almejado e, para sua efetivação, são necessárias a definição de etapas (metas) e ações (estratégias) que garantam os ideais planejados. $\mathrm{Na}$ visão, ainda de Bordignon (2014), Planos consolidam o planejamento, pois se caracterizam como um documento formal e legalmente aprovado.

O planejamento educacional no Brasil se estruturou em contextos políticos e econômicos ao longo de diferentes circunstâncias histórico-sociais, com desdobramentos na organização do sistema educacional. O resgate histórico do planejamento no Brasil revela que ele esteve sempre presente na vida pública brasileira e no pós-64 ganha maior expressividade, incorporando-se com maior força às ações do Estado, inclusive no campo educacional. É importante destacar que o planejamento ultrapassa a permanência dos militares no poder e compõe a sistematização das atividades de gestão pública (VIEIRA, 2014). 
Vieira (2014) ainda traz contribuições em relação ao desenvolvimento do planejamento educacional no Brasil expondo que:

\begin{abstract}
A introdução do planejamento educacional no Brasil se insere em um contexto mais amplo e coincide com o advento de estruturas de planejamento governamental criadas, de modo específico, a partir da segunda metade dos anos 1960, sob a égide dos governos militares. Foi então que surgiram os Planos Nacionais de Desenvolvimento (PNDs) e, como consequência, os Planos Setoriais de Educação e Cultura (Psecs) que caracterizaram as administrações daquele período. Fazendo uma retrospectiva no tempo e situando a discussão proposta no campo mais amplo do planejamento governamental, percebe-se que no passado os planos nacionais de governo foram marcos referenciais importantes para a concepção dos planos setoriais, aí incluídos os planos educacionais. (VIEIRA, 2014, p. 60)
\end{abstract}

O estudo em questão situa-se no contexto pós-Constituinte de 1988, no cenário democrático instaurado após a ditadura militar e sob a vigência atual do Plano Nacional de Educação (Lei n 13.005/2014). Nessa perspectiva, ressaltam-se alguns aspectos importantes no que se refere ao planejamento educacional brasileiro: a) a liderança e a forte participação das entidades da sociedade civil; b) o fortalecimento do regime de colaboração entre os entes federativos; c) o aumento da organização sistêmica, facilitando a articulação entre os sistemas de ensino; d) a associação entre diretrizes nacionais, sistemas e planos, com possibilidade de articulação do todo. (BORDIGNON, 2014).

Cumpre destacar que o otimismo decorrente do movimento democrático que resultou na aprovação da Lei 13.005/2014 (PNE) forneceu subsídios para o encaminhamento dos processos de monitoramento e avaliação (previstos em lei) dos Planos Estaduais (PEEs) e Municipais de Educação (PMEs). Scaff e Oliveira (2018) consideram que o caráter dinâmico do planejamento educacional e o processo participativo não se esgotam com a aprovação do seu resultado - o Plano - mas se estendem durante todo o período de execução, o qual requer avaliação contínua, de forma a monitorar o alcance das estratégias estabelecidas para a concretização de cada meta.

A importância do monitoramento e da avaliação previstos na legislação revelaram-se elementos-chave na condução das políticas públicas. Dourado, Grossi Junior e Furtado (2016) apontam que:

[...] os entes federativos devem ter clareza de que o monitoramento e a avaliação dos planos de educação tornam-se elementos imprescindíveis à tomada de decisões dos gestores públicos, visando a garantir a relação eficiência, eficácia e efetividade do que foi planejado, os possíveis ajustes no percurso, a participação da sociedade e a transparência necessária (DOURADO; GROSSI JUNIOR; FURTADO, 2016, p. 457) 
Nessa direção, o monitoramento nos PMEs justifica-se pelo seu papel estratégico exercido na condução da política educacional em nível municipal, pois o acompanhamento contínuo de diretrizes, metas e estratégias é primordial para o sucesso das políticas públicas.

\section{Monitoramento e avaliação das políticas educacionais}

O monitoramento e a avaliação das políticas educacionais são fundamentais à compreensão de seu encaminhamento e de seus resultados, uma vez que revelam as características inerentes aos processos de participação e condução das políticas públicas, possibilitando sua reorganização. Neste cenário, a compreensão da sua funcionalidade é necessária, pois fornece subsídios ao aprimoramento do planejamento educacional.

As pesquisas sobre o monitoramento e a avaliação das políticas públicas estão presentes em diversas áreas do conhecimento, com destaque para as ciências sociais, administração, economia, estatística, dentre outras. Essas áreas fornecem contribuições significativas ao entendimento e à condução das políticas educacionais. Januzzi (2011), em abordagem sobre a avaliação de programas sociais no Brasil, considera que:

O monitoramento e avaliação são processos analíticos organicamente articulados, que se complementam no tempo, com o propósito de subsidiar o gestor público de informações mais sintéticas e tempestivas sobre a operação do programa - resumidas em painéis ou sistemas de indicadores de monitoramento - e mais analíticas sobre o funcionamento deste, levantadas nas pesquisas de avaliação. (JANUZZI, 2011, p. 265)

É importante evidenciar que monitoramento e avaliação se correlacionam na execução das políticas, mas apresentam funções distintas. O Caderno de Estudos do Curso em Conceitos e Instrumentos para o Monitoramento de Programas do Ministério do Desenvolvimento Social, assim explana a diferença entre os termos:

Uma diferença entre a avaliação e o monitoramento é a capacidade da primeira de refletir uma relação de causa e efeito e a possibilidade de inferir um julgamento de valor a uma intervenção ou programa. Já o monitoramento verifica a realização regular e sistemática das atividades, seus produtos e resultados, comparando-os com parâmetros préestabelecidos. (BRASIL, 2016, p. 17)

A avaliação institui uma valoração a um programa ou política de Estado a partir de uma sistematização de objetivos, efetuado por avaliadores, sendo que a designação de valoração e julgamento gera aspectos qualitativos que distinguem situações simples ou complexas de acompanhamento das ações governamentais. Esse mecanismo permite ao governo reconhecer os resultados de um programa ou projeto, fazendo com que sejam criadas formas de aperfeiçoamento 
da concepção ou implementação das ações públicas, tornando-as mais concretas e transparentes. (RAMOS, 2012).

Aranda et al (2020) evidenciam que avaliar uma política, em seu processo de implementação - compreendido como monitoramento da vida útil de uma política, assim como na verificação seus desdobramentos e impactos ao término do ciclo - corresponde a examinar ações imprescindíveis para o sucesso de uma política.

As políticas públicas, além de avaliadas, são também monitoradas. No campo educacional, o Caderno de Orientações para Monitoramento e Avaliação dos Planos Municipais de Educação dispõe que:

\begin{abstract}
O monitoramento é um ato contínuo de observação, pelo qual são tornadas públicas as informações a respeito do progresso que vai sendo feito para o alcance das metas definidas. A avaliação é entendida como o ato periódico de dar valor aos resultados alcançados até aquele momento, às ações que estejam em andamento e àquelas que não tenham sido realizadas, para determinar até que ponto os objetivos estão sendo atingidos e para orientar a tomada de decisões (BRASIL, 2016, p. 6).
\end{abstract}

É importante destacar que ambos os processos devem se articular, buscando o alcance das metas, a partir de releituras constantes em que são possíveis identificar e corrigir eventuais demandas advindas do processo educacional local.

Nesse sentido, a complexidade de sistematização dos processos de monitoramento e a avaliação dos Planos de Educação emanadas no contexto da Lei n¹3.005/0214 fizeram com que o MEC estipulasse uma rede de esforço colaborativo que envolveu as secretarias estaduais e municipais, fóruns de educação, Conselho Nacional de Secretários de Educação (CONSED), a União Nacional dos Dirigentes Municipais de Educação (UNDIME), entre outros.

Esse esforço culminou na elaboração de publicações organizadas pela SASE/MEC (Secretaria de Articulação com os Sistemas de Ensino) e INEP ((Instituto Nacional de Estudos e Pesquisas Educacionais Anísio Teixeira) que nortearam os processos de monitoramento e avaliação dos planos, contribuindo para a definição dos cenários e das políticas educacionais vigentes em esferas regionais e locais, inclusive no município de Taubaté.

\title{
Metodologia
}

O estudo - ancorado no campo das políticas educacionais - optou por uma abordagem metodológica de natureza qualitativa. Gerhardt (2009) aponta que "as características da pesquisa qualitativa compreendem: objetivação do fenômeno; hierarquização das ações de descrever, compreender, explicar, precisão das relações entre o global e o local em determinado fenômeno" 
[...]. Nessa direção, André (2014) expõe que as pesquisas qualitativas vieram a se constituir em uma modalidade investigativa que se consolidou para responder ao desafio da compreensão dos aspectos formadores do humano, de suas relações e construções culturais, em suas dimensões grupais, comunitárias ou pessoais.

O estudo do Plano Municipal de Educação de Taubaté (2015-2025) fundamentou-se em um percurso metodológico baseado em pesquisa bibliográfica, análise documental e realização de entrevistas semiestruturadas com técnicos da Secretaria Municipal de Educação (SME), Comissão de Educação da Câmara e membros do Conselho Municipal de Educação (CME) que participaram do processo e foram acessados como informantes - chave, capazes de fornecer um conjunto de informações relevantes sobre o processo em questão.

A análise documental do Plano Municipal de Educação (PME) foi elaborada a partir do estudo das leis, decretos, planos, normas internas, atas, programas e projetos, com vistas a identificar diretrizes da política educacional do município. As fontes documentais analisadas incluíram a descrição das características organizacionais do sistema de ensino como: atribuições de equipes de supervisão; organização dos projetos internos e externos à pasta; relação normativalegal e institucional entre a Secretaria Municipal de Educação, o Conselho Municipal de Educação e o Conselho de Educação da Câmara, assim como a apresentação dos dados socioeconômicos e indicadores externos da educação básica.

Cellard (2012) afirma que o conhecimento satisfatório da conjuntura política, econômica, social, cultural favorece a apreensão dos esquemas conceituais de seus autores, identificando elementos do convívio social que permitem ao pesquisador compreender em excelentes condições as particularidades da organização social, não emitindo juízo de valor atual.

Como complemento à análise documental, foram realizadas entrevistas semiestruturadas que trouxeram contribuições significativas à compreensão do processo de monitoramento e avaliação do Plano Municipal de Educação de Taubaté. Quanto à vantagem da aplicação das entrevistas, Ludke (2018) elucida que:

\footnotetext{
A grande vantagem da entrevista sobre outras técnicas é que ela permite a captação imediata e corrente da informação desejada, praticamente com qualquer tipo de informante e sobre os mais variados tópicos. Uma entrevista benfeita pode permitir o tratamento de assuntos de natureza estritamente pessoal e íntima, assim como temas de natureza complexa e de escolhas nitidamente individuais. Pode permitir o aprofundamento de pontos levantados por outras técnicas de coleta de alcance mais superficial, como o questionário. (LUDKE, 2018, p. 39).
}

Dessa forma, o percurso metodológico apoiou-se em um processo de análise dos dados que procurou fornecer respostas ao problema de pesquisa e aos objetivos deste trabalho, com o 
intuito de estabelecer categorias, por meio de codificação, tabulação e interpretação dos dados, buscando fornecer subsídios para a compreensão da política municipal de educação no que condiz ao monitoramento e avaliação do Plano Municipal de Educação (PME).

O monitoramento e a avaliação do PME de Taubaté: breve painel dos documentos oficiais

O processo de monitoramento e avaliação do Plano Municipal de Educação ocorreu em consonância com os pressupostos legais e normativos do Plano Nacional de Educação (Lei n¹3.005/2014) e do Plano Estadual de Educação de São Paulo (Lei n 16.279/2016).

No caso de Taubaté, este processo foi estabelecido por meio da Lei Complementar no 392 , de 15 de julho de 2016, que instituiu como instâncias competentes para o monitoramento e avaliação: a Secretaria Municipal de Educação - SME; a Comissão de Educação da Câmara dos Vereadores; o Conselho Municipal de Educação - CME e o Fórum Municipal de Educação (FME). A Lei Complementar ainda estabeleceu uma periodicidade bienal de publicação dos relatórios de monitoramento e avaliação. Esses relatórios fundamentaram-se nas orientações existentes na publicação intitulada Caderno de Orientações para Monitoramento e Avaliação dos Planos Municipais de Educação, expedida pela SASE/MEC no ano de 2016.

Em 2016, o município assinou o termo de adesão à assistência técnica para monitoramento e avaliação dos Planos de Educação, em que se responsabilizou por: a) mobilizar as instituições responsáveis pelo processo de monitoramento e avaliação; b) viabilizar a participação dos representantes da comissão coordenadora nas formações oferecidas pela SASE/MEC; c) disponibilizar informações referentes ao processo de monitoramento e avaliação e d) indicar um técnico responsável pela interlocução com a SASE/MEC.

As ações coordenadas pela Secretaria Municipal de Educação, em parceria com a SASE/MEC, resultaram no Relatório Anual de Monitoramento do PME - Taubaté (versão preliminar), publicado em 17 de novembro de 2017, e no Relatório de Avaliação do Plano Municipal de Educação - PME de Taubaté, publicado em 18 de dezembro de 2018. Ambos os documentos foram elaborados em consonância com a metodologia proposta pelo Caderno de Orientações para Monitoramento e Avaliação dos Planos Municipais de Educação (2016).

No tocante às conclusões, os relatórios de monitoramento e avaliação de Taubaté apontaram a necessidade de o município construir uma base de dados, uma série histórica e uma metodologia capazes de atender a realidade local.

Evidenciou-se que para o cumprimento desta demanda era necessária a existência de um número maior de técnicos qualificados para dar continuidade a uma proposta de metodologia local 
de monitoramento e avaliação. $\mathrm{Na}$ conjuntura institucional, percebeu-se que a viabilidade dessa condição supera a contratação de técnicos, e indica a necessidade de construção de um processo reflexivo e autônomo capaz de estimular a participação social.

A publicação dos relatórios referentes ao primeiro ciclo de monitoramento do município de Taubaté contou com parceria da SASE/MEC, sendo notória sua influência na elaboração e na concepção dos documentos, conforme já discutido. Cabe mencionar que a Secretaria de Articulação com os Sistemas de Ensino foi extinta em 2019, pelo decreto $n^{\circ} 10.195$, de 30 de dezembro de 2019, o que impactou significativamente a continuidade e sistematização dos trabalhos em nível local.

Diante deste cenário, considera-se relevante a contribuição de Dourado, Grossi Junior e Furtado (2016) sobre o monitoramento e avaliação:

\begin{abstract}
No que se refere ao processo de monitoramento e avaliação, não existe fórmula pronta que possa ser replicada em todos os lugares, mas, sim, a necessidade de que todos os cidadãos - principalmente os gestores e profissionais da educação - articulados aos responsáveis legais por esse processo - coloquem em prática tudo que foi pensado, discutido e transformado em lei, que, em realidade, consta dos planos de educação, e de que os ajustes necessários sejam feitos no percurso. Trata-se de um processo complexo que irá requerer mobilização permanente da sociedade civil e política e, especialmente, dos atores definidos nos planos como responsáveis pelo monitoramento e pela avaliação. (DOURADO; GROSSI JUNIOR; FURTADO, 2016, p.459)
\end{abstract}

Entende-se que o protagonismo decorrente da ação dos agentes responsáveis pelo processo monitoramento e avaliação dos PMEs é essencial para compreender os cenários vivenciados pelos municípios. Este estudo optou por correlacionar as informações contidas nos relatórios de monitoramento e avaliação do PME de Taubaté, com as declarações de informantes-chave da Secretaria Municipal de Educação, da Comissão de Educação da Câmara de Vereadores e do Conselho Municipal de Educação envolvidos diretamente na implementação da política educacional local, fortalecendo as análises conclusivas propostas na pesquisa em questão.

O monitoramento e avaliação do PME de Taubaté: percepções de atores envolvidos no processo

As percepções provenientes dos técnicos da SME, da Comissão de Educação da Câmara e do CME quanto ao processo de elaboração, monitoramento e avaliação do PME de Taubaté são fundamentais para a compreensão do desenvolvimento deste em nível municipal.

Para a realização das entrevistas semiestruturadas foram escolhidos técnicos das três instâncias envolvidas no acompanhamento contínuo do PME, levando-se em conta o tempo de 
permanência no serviço público e o envolvimento destes agentes com o plano desde sua elaboração até o seu monitoramento e avaliação.

A coleta de dados foi realizada no ano de 2020 em diferentes momentos e sob o contexto de uma pandemia global em que os procedimentos metodológicos sofreram adaptações para adequar-se à conjuntura. Os entrevistados foram contatados por telefonemas, a partir dos dados fornecidos pela SME e as entrevistas semiestruturadas ocorreram no formato on-line. Ao todo foram entrevistados: três sujeitos pertencentes ao quadro técnico da Secretaria Municipal de Educação e um vereador cidade de Taubaté. É importante salientar que os sujeitos entrevistados exerceram as seguintes funções no contexto do PME de Taubaté: coordenação geral de elaboração do PME (sujeito 1); responsável técnico pelos relatórios de monitoramento e avaliação do PME (sujeito 2); presidência do CME (sujeito 3) e presidência da Comissão da Educação da Câmara (sujeito 4).

A organização do material coletado nas entrevistas consolidou os objetivos iniciais da pesquisa e seu processo de análise documental. Para compreender o depoimento dos entrevistados, optou-se por organizar o material em seis eixos de análise: I. Parceria com a Secretaria de Articulação com os Sistemas de Ensino (SASE/MEC); II. Sistematização e intepretação de dados do PME; III. Participação na elaboração do Plano; IV. Ações de acompanhamento e avaliação do PME; V. Periodicidade de acompanhamento e avaliação do PME e VI. Dificuldades no acompanhamento e avaliação do PME.

Os sujeitos de pesquisa 1 e 2 envolvidos diretamente com a elaboração, implementação e o acompanhamento do plano através de sua atuação junto à Secretaria Municipal de Educação forneceram contribuições aos eixos de análise I, II e III. Já os sujeitos 3 e 4 envolvidos com o Conselho Municipal de Educação e a Comissão de Educação da Câmara, colaboraram com os eixos de análise IV, V e VI.

As declarações do eixo de análise I (Parceria com a Secretaria de Articulação com os Sistemas de Ensino), revelaram que a assessoria exercida pela SASE/MEC na elaboração, no monitoramento e na avaliação dos planos foi crucial para o desenvolvimento dos trabalhos em nível local, isso porque esta Secretaria sistematizou um processo de formação contínua em nível nacional com acompanhamento técnico.

As falas indicam que houve reciprocidade entre as esferas de governo no que condiz à parceria entre o município e a SASE/MEC. Destaca-se a preocupação quanto à necessidade de trabalhar em regime de colaboração e o processo formativo do órgão federal junto aos municípios, focado no esclarecimento de dúvidas e orientações relativas ao levantamento de dados estatísticos, 
elementos fundamentais na conclusão dos relatórios. Os entrevistados apontaram que, apesar da assessoria técnica federal, o município encontrou dificuldades na obtenção dos dados estatísticos relativos à Educação Básica e a Educação Superior no que concerne às Instituições Estaduais e Privadas de Ensino, com reflexos no relatório de monitoramento.

As assertivas sobre o eixo de análise II (Sistematização e intepretação de dados do PME), deixaram evidente que a coleta de dados respeitou o contexto histórico da educação municipal. Cumpre salientar que o Plano de Educação fez referência aos dados adquiridos junto ao governo federal e não citou a existência de indicadores municipais de monitoramento de suas metas e estratégias.

As declarações ainda revelaram que na fase de coleta e sistematização dos dados existiram problemas no uso das plataformas e na periodicidade de publicação dos dados, o que acarretou dificuldades para sua intepretação. Esse fato reforça a complexidade existente no processo de sistematização e interpretação dos dados com vistas ao monitoramento e avaliação do plano, isso porque a capacidade de gerenciamento técnico em nível local é limitada, conforme indicam as conclusões presentes nos relatórios.

As falas que compuseram o eixo de análise III (Participação na elaboração do Plano), evidenciaram que, para viabilizar a participação social na elaboração do PME de Taubaté, a Secretaria Municipal de Educação levou em conta a utilização de mecanismos de divulgação (imprensa, internet, cartas - convite, entre outros), para dar ampla publicidade ao plano, porém com baixa adesão e manifestação de diferentes segmentos envolvidos na elaboração do plano. Os Fóruns constituíram-se como instrumentos de divulgação e discussão do plano em escala local.

No tocante ao eixo de análise IV (Ações de acompanhamento e avaliação do PME), as falas indicam que o Conselho Municipal de Educação monitorou os procedimentos e normas que regem as ações de acompanhamento e avaliação do PME, em concordância com a legislação vigente no município. Os apontamentos revelaram que as ações de acompanhamento e avaliação do PME efetivam-se por meio das audiências de metas fiscais, que analisam o direcionamento e os investimentos dos recursos realizados pela Prefeitura na educação municipal. A Comissão de Educação da Câmara realizou Audiências Públicas para acompanhar e analisar os indicadores externos de avaliação aplicados ao município.

Vale ainda destacar que a periodicidade de acompanhamento e avaliação do PME (Eixo de análise V) foi realizada mensalmente pelo Conselho Municipal de Educação e quadrimestralmente pela Comissão de Educação da Câmara. 
O eixo de análise VI (Dificuldades no acompanhamento e avaliação do PME) evidenciou problemas na organização e sistematização dos trabalhos no CME devido ao curto espaço de tempo concedido para o atendimento às demandas e ao acúmulo de funções.

Outro apontamento relevante referiu-se à falta de acesso rápido às informações, em virtude da inexistência de uma plataforma integrada de coleta e armazenamento de dados entre o CME e as instituições públicas e privadas de ensino (Educação Básica e Ensino Superior), o que limita a produtividade e causa uma relação de dependência em relação à base de dados do Governo Federal.

Destaca-se ainda nas falas, a falta de continuidade na publicidade e divulgação dos dados, pois a municipalidade não conta com uma estrutura integrada de análise e acompanhamento do Plano, amparada por meios eficientes de comunicação. As declarações da Comissão de Educação da Câmara não apontaram dificuldades no acesso aos dados e no processo de acompanhamento e avaliação do PME, sendo que há uma relação de simetria entre a Secretaria de Educação e o Legislativo.

As seis categorias de análise resultantes das falas revelaram diferentes posicionamentos sobre os temas tratados e contribuíram para evidenciar como ocorre o processo de monitoramento e avaliação do PME de Taubaté.

É compreensível que a fala e a percepção dos sujeitos indicaram avanços e retrocessos na condução dessas etapas que necessitam de constante reavaliação em suas metas e estratégias. Essa reavaliação aumenta a confiabilidade nos dados e consolida ações estratégicas para o cumprimento das metas do PME, contribuindo, assim, para o desenvolvimento da política educacional local. É importante salientar que o Município de Taubaté ainda não publicou seu $2^{\circ}$ Relatório de Monitoramento e Avaliação do PME, embora este seja compreendido como condição necessária para a reavaliação das metas e estratégias de seu Plano de Educação.

\section{Considerações}

O estudo forneceu contribuições à intepretação das características sociopolíticas e administrativas que perfazem a condução das políticas educacionais no município. Cabe mencionar que Taubaté não possuía nenhum instrumento de planejamento educacional vigente até a aprovação de seu Plano Municipal de Educação em 2015.

Nessa conjuntura, destaca-se a importância do PME enquanto instrumento local de planejamento que fornece contribuições à organização e ao funcionamento da educação no município. A existência deste instrumento legal que contém diretrizes, metas e estratégias e prevê 
mecanismos de participação social, favorece o direcionamento das ações do poder público e o envolvimento da sociedade civil na educação local.

As políticas públicas municipais foram elaboradas em consonância com os entes federados, mas deve-se atentar ao fato que essa proximidade entre eles, produz uma relação de interdependência que se manifesta na concepção das políticas públicas em educação.

O memorial descritivo do PME de Taubaté deixa claro que a elaboração do Plano seguiu as orientações propostas nas publicações e formações provenientes da SASE/MEC (extinta em 2019), evidenciando uma limitação técnica existente em nível local decorrente de fatores como: número insuficiente de técnicos para acompanhamento do Plano; curto prazo de tempo para formulação e implementação do PME; qualificação insuficiente das equipes envolvidas para elaboração de um Plano Municipal que atendesse às diretrizes do PNE, mas que respondesse com autonomia as demandas locais; restrições orçamentárias.

No que condiz ao monitoramento e avaliação, os relatórios publicados em 2017 e 2018 foram estruturados na proposta metodológica do PNE em Movimento: Caderno de Orientações para o Monitoramento e Avaliação dos Planos Municipais de Educação. Os documentos analisados revelam que o município seguiu rigorosamente a proposta, concluindo os Relatórios dentro dos prazos estabelecidos no primeiro ciclo, mas as discussões que envolveram os resultados alcançados indicam contribuições parciais das instâncias implicadas nesse processo (Secretaria de Educação, Conselho Municipal de Educação, Fórum Municipal de Educação, entidades da sociedade civil, entre outros), sendo necessária uma revisão dos procedimentos de publicização e mobilização social com o intuito de promover a revisão constante das metas e estratégias contidas no PME.

O monitoramento e a avaliação do PME de Taubaté dependem da consolidação de espaços participativos que promovam uma discussão qualificada sobre os dados contidos nos relatórios, visando à contínua reavaliação das metas e estratégias. Isto se faz necessário, pois a realidade educacional do município não é estática e depende de fatores que estão condicionados à dinâmica política implícita em seu território.

Deve-se considerar que os órgãos de representação (Conselhos, Fóruns, entre outros), previstos em legislação municipal, devem se tornar espaços institucionalizados de representação social, por meio dos quais os cidadãos possam manifestar seu posicionamento sobre o PME de Taubaté, avaliando demandas e propondo soluções. É relevante destacar que esta proposta não se faz inovadora diante da estrutura normativa e legal criada desde a Constituição de 1988, mas é indispensável o incentivo aos mecanismos que aproximam o poder público da sociedade civil. 


\section{Referências}

ANDRÉ, Marli; GATTTI, Bernardete A. Métodos qualitativos de pesquisa em educação no Brasil: origens e evolução. Programa de formação em pesquisa e pós-graduação. Módulo VII. Pesquisa Qualitativa, parte II, v. 26, 2014. Disponível em:

http:/ / www.scielo.br/scielo.php?script=sci_arttext\&pid=S0104-

40602017000100103\&lng=en\&nrm=iso . Acesso em: 20 fev. 2020.

ARANDA, Maria Alice de Miranda; RODRIGUES, Evally Solaine de Souza; MILITAO, Sílvio Cesar Nunes. Monitoramento e Avaliação dos Planos Decenais de Educação: a produção do conhecimento no Brasil. Educ. rev. [online]. 2020, vol.36. Disponível em: https:/ / www.scielo.br/scielo.php?script=sci_abstract\&pid=S0104$40602020000100203 \& \operatorname{lng}=$ en\&nrm=iso\&tlng=pt. Acesso em: 05 jul. 2020.

BORDIGNON, Genuíno. Planos de governo e políticas de estado: muitos planos, pouco planejamento. In: SOUZA, Donaldo Bello de; MARTINS, Ângela Maria (Org.). Planos de educação no Brasil: planejamento, políticas, práticas. São Paulo: Loyola, p. 29-53, 2014.

BRASIL, Decreto $n^{\circ} 10.195$, de 30 de dezembro de 2019. Aprova a Estrutura Regimental e o Quadro Demonstrativo dos Cargos em Comissão e das Funções de Confiança do Ministério da Educação e remaneja e transforma cargos em comissão e funções de confiança. Diário Oficial da União, Brasília, DF, 31 dez. 2019. Disponível em: https://www.in.gov.br/web/dou/-/decreto-n-10.195de-30- de-dezembro-de-2019-236099560. Acesso em 12 jan.2021.

BRASIL. Lei n 13.005 de 25 de junho de 2014. Aprova o Plano Nacional de Educação e dá outras providências. Disponível em: http://www.planalto.gov.br/ccivil_03/_ato2011-

2014/2014/lei/113005.htm. Acesso em: 5 dez. 2020.

BRASIL. Ministério do Desenvolvimento Social e Combate à Fome. Universidade Federal do Rio Grande do Sul. Caderno de estudos do Curso em Conceitos e Instrumentos para o Monitoramento de Programas. Brasília, DF: MDS, Secretaria de Avaliação e Gestão da Informação, Secretaria Nacional de Assistência Social; Centro de Estudos Internacionais sobre o Governo, 2016. 96p. Disponível em: https:/ / aplicacoes.mds.gov.br/sagirmps/ferramentas/docs/CEGOV\%20202015\%20-\%20MDS\%20Monitoramento\%20Caderno\%20de\%20Estudos.pdf. Acesso em 20 jun.2020.

BRASIL. Ministério da Educação. Caderno de Orientações para Monitoramento e Avaliação dos Planos Municipais de Educação/ Secretaria de Articulação com os Sistemas de Ensino (MEC/SASE), 2016. Disponível em:

http://pne.mec.gov.br/images/pdf/publicacoes/pne_pme_caderno_de_orientacoes_final.PDF. Acesso em 10 set. 2020.

CELLARD, André. Análise documental. In: POUPART, Jean et al. (Orgs). A pesquisa qualitativa:

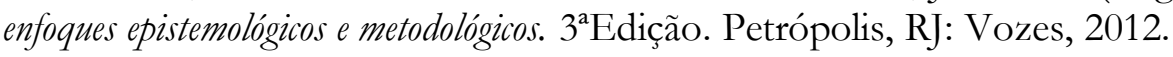

CURY, Carlos Roberto Jamil . O plano nacional de educação: duas formulações. Cadernos de Pesquisa, São Paulo, n. 104, p. 162-180, 1998. Disponível em:

https://www.scielo.br/pdf/cp/v41n144/v41n144a08.pdf. Acesso em: 10 fev. 2021. 
DOURADO, Luiz Fernandes; GROSSI JUNIOR, Geraldo; FURTADO, Roberval Angelo. Monitoramento e avaliação dos planos de educação: breves contribuições. Revista Brasileira de Política e Administração da Educação - Periódico científico editado pela ANPAE, [S.1.], v. 32, n. 2, p. 449 - 461, ago. 2016. Disponível em: https://www.seer.ufrgs.br/rbpae/article/view/ 67198. Acesso em: 24 mai. 2020.

GERHARDT, Tatiana Engel; SILVEIRA, Denise Tolfo. Métodos de pesquisa. Plageder, 2009.

JANNUZZI, P.M. Avaliação de programas sociais no Brasil: repensando práticas e metodologias das pesquisas avaliativas. Planejamento e políticas públicas, n. 36,jan./jul. 2011.Disponível em: https://www.ipea.gov.br/ppp/index.php/PPP/article/view/228. Acesso em: 25 mai. 2020.

LUDKE, Menga; ANDRÉ, Marli E. D. A. Pesquisa em educação: abordagens qualitativas. 2. ed. Rio de Janeiro: E.P.U., 2018.

PNUD. Índice de desenvolvimento humano municipal brasileiro. - Brasília: PNUD, Ipea, FJP, 2013. 96 p. - (Atlas do Desenvolvimento Humano no Brasil 2013). Disponível em:https://www.ipea.gov.br/portal/images/stories/PDFs/130729_AtlasPNUD_2013.pdf. Acesso em: 11 mai. 2020.

RAMOS, Marília Patta; SCHABBACH, Letícia Maria. O estado da arte da avaliação de políticas públicas: conceituação e exemplos de avaliação no Brasil. Rev. Adm. Pública, Rio de Janeiro, v. 46, n. 5, p. 1271-1294, Out. 2012. Disponível em:

http:/ / www.scielo.br/scielo.php?script=sci_arttext\&pid=S0034-

76122012000500005\&lng=en\&nrm=iso. Acesso em: 24 jun. 2020.

SÃO PAULO. Lei no 16.279, de 08 de julho de 2016. Aprova o Plano Estadual de Educação de São Paulo e dá outras providências. Disponível em: https://governo-

sp.jusbrasil.com.br/legislacao/359651717/lei-16279-16-sao-paulo-sp. Acesso em: 12 mai. 2020.

SCAFF, Elisangela Alves da Silva; OLIVEIRA, Marli dos Santos. Planos decenais de educação: sistematização do monitoramento e avaliação nos cenários estadual e municipal. Série-Estudos UCDB - Campo Grande, MS, v. 23, n. 47, p. 141-162, jan./abr. 2018. Disponível em: https://www.serie-estudos.ucdb.br/serie-estudos/article/view/1081. Acesso em: 10 mar. 2021.

SOUZA, Celina. Políticas públicas: uma revisão da literatura. Sociologias, Porto Alegre, n.16, p.2045, dez. 2006. Disponível em: http://www.scielo.br/scielo.php?script=sci_arttext\&pid=S151745222006000200003\&lng=en\&nrm=iso. Acesso em 25 Abr. 2020.

TAUBATÉ. Lei Complementar n³92, de 15 de julho de 2016. Institui o Plano Municipal de Educação e dá outras providências. Taubaté: Câmara Municipal, [2016]. Disponível em: http://www.camarataubate.sp.gov.br/abrir_arquivo.aspx/Lei_Complementar_39 2_2016? cdLocal $=5$ \&arquivo $=\{3$ CA4BB44-DE33-CDA8-BEC4-BD5ADAACDC13 $\} \cdot$ pdf. Acesso em 06 out. 2019.

TAUBATÉ, Prefeitura Municipal. Relatório de Avaliação do Plano Municipal de Educaşão - PME Taubaté. Lei Complementar n 392/2016. [2018]. Disponível em:

http:/ / taubate.educaon.com.br/plano-municipal-de-educacao-de- taubate. Acesso em 16 ago. 2020. 
TAUBATÉ, Prefeitura Municipal. Relatório Anual de Monitoramento do PME - Plano Municipal de Educação de Taubaté. Lei Complementar n 392/2016. [2017]. Disponível em:

http://simec.mec.gov.br/pde/relatorioMonitoramento.php\#. Acesso em: 15 ago. 2020.

VIEIRA, Lerche Sofia. Planos e políticas educacionais: das concepções às práticas. In: SOUZA, Donaldo Bello, MARTINS, Angela Maria (orgs). Planos de educação no Brasil: planejamento, políticas, práticas. São Paulo: Edições Loyola, p. 55-71, 2014. 